\title{
O AMBIENTE DE TRABALHO NO SETOR BANCÁRIO E O BEM-ESTAR ${ }^{1}$
}

\author{
Cynthia Suennia Damasceno Lucena de Paiva ${ }^{*}$ \\ Lívia de Oliveira Borges"
}

\begin{abstract}
RESUMO. O século XXI passa por transformações da estruturação produtiva, e o trabalho bancário foi um dos setores atingidos. Dada a importância de compreender como, neste contexto, encontram-se os bancários no tocante ao seu bem-estar, desenvolveu-se uma pesquisa que investiga o ambiente de trabalho no setor bancário e o bem-estar desses trabalhadores. Como norte teórico da pesquisa utilizou-se o modelo ecológico de saúde mental. Aplicou-se um questionário a 200 bancários, dos quais $58,1 \%$ são do sexo masculino, $60,9 \%$ são casados e $28,4 \%$, solteiros. Como um dos resultados constatou-se que a quase-totalidade dos fatores ambientais repercutiram positivamente na saúde mental, com exceção das relações interpessoais. Parte da amostra apresentou indicativos de depressão e insatisfação com a vida. Conclui-se que o ambiente de trabalho pode exercer impacto sobre o bem-estar do trabalhador. Os resultados podem ser úteis para fundamentar intervenções profissionais.

Palavras-chave: bem-estar, bancários, reestruturação produtiva.
\end{abstract}

\section{THE WORK ENVIRONMENT IN BANKS AND THE WELL-BEING}

\begin{abstract}
The XXI Century passes by transformations on the productive restructuration and the banking work was one of the affected sectors. Understanding how to be the bank workers' well-being in this context is a matter of great concern. Then, a research was developed to investigate the banking environment and the bank workers' well-being. The ecological model of mental health was considered to be the guideline of research. 200 bank workers participated in this research study, $41,9 \%$ were female and 58, $1 \%$ were male, $60,9 \%$ were married and 28, $4 \%$ were single. Among the results, quite the environmental factors that have great influence to the mental health were satisfactory, except the interpersonal relationship. Part of the sample presented indicative signs of depression and life insatisfaction. It was concluded that the work environment provides impacts to the worker's well-being. The results can offer theoretical support to professional interventions.
\end{abstract}

Key words: Well-being, bank workers, productive restructuration.

\section{EL AMBIENTE LABORAL EN EL SECTOR BANCARIO Y EL BIENESTAR}

RESUMEN. El siglo XXI pasa por transformaciones de reestructuración productiva y el trabajo bancario fue uno de los sectores atingidos. Comprender como se encuentra el bienestar de los bancarios en este contexto es inquietante. Entonces, se desarrolló una investigación que focaliza el sector bancario y el bienestar de los trabajadores. Fue considerada como orientación teórica de la investigación, el modelo ecológico de salud mental. Cuestionarios fueran aplicados en 200 bancarios, siendo $41,9 \%$ de ellos del sexo femenino y $58,1 \%$ del masculino; $60,9 \%$ son casados y $28,4 \%$, solteros. Entre los resultados, casi la totalidad de los factores ambientales en la repercusión para la salud mental fueron positivos, con excepción de las relaciones interpersonales. Parte de la muestra presentó indicativos de depresión e insatisfacción con la vida. Se concluye que el ambiente laboral puede tener impactos en el bienestar del trabajador. Los resultados pueden ser útiles para fundamentar intervenciones profesionales.

Palabras-clave: Bienestar, bancarios, reestructuración productiva.

O termo reestruturação produtiva está sendo utilizado para designar o processo de mudanças ocorrido nas empresas nas últimas décadas, com a introdução de inovações, tanto tecnológicas quanto de

\footnotetext{
Apoio: CAPES.

* Mestre em Psicologia. Professora do Centro Federal de Educação Tecnológica de Rio Verde (CEFET-RF).

\# Doutora em Psicologia. Professora da Universidade Federal Minas Gerais. Pós-doutora pela Universidade Complutense de Madrid.
} 
gestão, buscando-se alcançar uma organização de trabalho integrada e flexível (Ferreira, 1986; Garay, 2001). Nos bancos brasileiros, a exemplo de outros setores da economia, esse fenômeno constituiu-se em um processo heterogêneo, no sentido de desenvolverse em ritmos diferentes em cada região brasileira e em cada rede bancária. Ele se tornou evidente a partir da década de 1960, com a criação dos centros de processamento de dados (CPDs) para responder "às necessidades de processamento de um grande volume de documentos gerados pelas diversas operações realizadas pelos bancos" (Filgueiras, 2001, p. 284). A partir daí o processo vem paulatinamente abrangendo medidas organizacionais, como: automação dos serviços (por exemplo: bancos 24 horas; agências on line; caixas automáticos, etc.); redução de custos; telemarketing; terceirização de atividades; estrutura organizacional mais horizontal, com tendências a predominarem nas agências apenas dois níveis herárquicos, restritos a gerentes e atendentes (Filgueiras, 2001; Laranjeiras, 1997; Segnini, 1999).

Tais medidas organizacionais, entre outros aspectos, têm respondido, a partir de 1995 , a políticas do Governo Federal, que acelerou o processo de privatização e aprofundou a desregulamentação do mercado financeiro, introduzindo empresas nãobancárias que operam no mercado de capitais e retirando dos bancos o monopólio das operações de crédito. Intensificou-se a concorrência entre os bancos estrangeiros, ocasionando falências de uns e privatização de outros (Araújo, Cartoni \& Justo, 2001).

Para os bancários, um dos desdobramentos de tal fenômeno é a descaracterização do emprego bancário como seguro para toda uma vida ocupacional. A título de ilustração, em dezembro de 1989 havia 824.316 empregados no setor financeiro no Brasil, enquanto em dezembro de 1996 estes eram apenas 497.108 (Cadastro Geral dos Empregados e Desempregados Lei 4.923/65 - Elaboração: DIEESE - Sub/Rio).

Mudaram também os requisitos exigidos dos bancários, que precisam agora ser polivalentes, flexíveis e ter um nível mais alto de escolaridade (Filgueiras, 2001). Essas exigências contrastam com o período precedente, quando o bancário era incentivado à dedicação integral ao trabalho e, em muitos casos, a interromper a educação formal. A informação passou a ser a ferramenta fundamental do trabalhador e ele necessita ter a capacidade de interpretá-la e de dominar o manuseio das novas tecnologias (DIEESE, 1997).

Mudaram ainda as possibilidades de mobilização e organização trabalhista dos bancários. A redução do contingente, como já assinalado, e o medo da demissão, fizeram diminuir a sindicalização e a mobilização na defesa de direitos adquiridos e por novas conquistas. Tais fatos são evidentes se acompanhadas as notícias na imprensa.

Este bancário desafiado pelas mudanças é o alvo da presente pesquisa, cujo objetivo é compreender a saúde mental do bancário a partir de suas condições do ambiente de trabalho.

\section{SAÚDE MENTAL}

O conceito de saúde evoluiu ao longo do tempo. Sob o modelo biomédico, por exemplo, seguiu a concepção cartesiana, segundo a qual há uma rigorosa divisão entre mente e corpo, com total independência entre um e o outro, portanto as questões de ordem psicológica igualmente são tanbém totalmente independentes das de ordem social, biológica e ambiental (Capra, 1982; Ogden, 1999; Spink, 1992; Vaitsman, 1992).

Em seguida, conforme Ogden (1999) e Bücher (2003), a influência da psicossomática desafiava o modelo médico tradicional e respondia ao modelo freudiano mente/doença física. A psicossomática provocou reações diferenciadas nos profissionais de saúde, alertando para a necessidade de esses profissionais ampliarem o conceito de saúde para garantir maior respeito às reais necessidades da população assistida.

Outro alerta veio da ação da Organização Mundial de Saúde, que define saúde como "um estado de completo bem-estar físico, mental e social, e não somente a ausência de enfermidades" (OMS, 1948). Neste conceito, são várias as facetas que influenciam a saúde do indivíduo e devem ser consideradas na sua compreensão. Tal conceito levou à superação da noção de que a ausência de doença era critério suficiente de saúde e enfatizou a importância de medidas preventivas para mantê-la, tais como atitudes/comportamentos que levam à manutenção e/ou melhoramento da saúde. O mesmo conceito conduz a considerar, também, as várias esferas de vida de um indivíduo, tais como o trabalho, as relações familiares, o lazer, etc.

Esta nova visão de saúde influenciou várias ciências, entre as quais a Psicologia. A partir da década de 1980 desenvolveu-se a Psicologia da Saúde, ramo da psicologia voltado a essa visão. O desdobramento dessa evolução nas pesquisas se manifestam inclusive na natureza das variáveis consideradas, que passaram a se referir aos contextos sociais, culturais e ambientais (Ogden, 1999). 
Por consequiência, surgiram vários modelos com o intuito de explicar a saúde mental ou o bem-estar psíquico. A presente pesquisa fundamentou-se no modelo de saúde mental ecológico de Warr (1987), visto que relaciona aspectos psíquicos individuais com aspectos sociais e estuda a saúde mental como um processo que se desenvolve a partir dessas relações. Warr (1987) relaciona cinco dimensões que integram a saúde mental, quais sejam: 1)bem-estar afetivo (quando o indivíduo sente-se bem internamente), dimensão muito relacionada com a auto-estima; 2) competência, um dos recursos psicológicos de que as pessoas se utilizam para resolver variados tipos de problema; 3) autonomia (que significa ter habilidades pessoais para resistir às influências ambientais e construir sua própria opinião e ação); 4) aspiração, que consiste em manter o interesse em engajar-se no ambiente, procurar crescer e desenvolver-se; e 5) funcionamento integrado, que se refere-se à pessoa como um todo, perfazendo as múltiplas correlações entre os outros quatro componentes.

Warr (1987) considera que a saúde mental, em tais dimensões, é afetada pelos aspectos ambientais. Estes têm efeitos distintos, por isso para explicar tal relação o autor recorre didaticamente à sua analogia com a relação entre as vitaminas e a saúde corporal. Observa que o organismo adoece quando as vitaminas lhe faltam. À medida que ingere determinados níveis de vitaminas, gradativamente, o organismo vai tendo melhoras em seu estado. No decorrer do tempo, no entanto, a ingestão de algumas vitaminas deixará de gerar benefício, tornando-se constantes as reações do organismo. Warr (1987) chamou a essas vitaminas de EC, que significam "efeito constante". Por outro lado, determinadas vitaminas, se consumidas em excesso, tendem a prejudicar o organismo: são as chamadas vitaminas DA, que significam "diminuição adicional".

Warr (1987) enumerou nove aspectos ambientais, sendo seis do tipo DA e três, EC:

1. oportunidade para exercer controle sobre o meio, a qual se dá à proporção que as condições do ambiente social oportunizam ao indivíduo controlar suas atividades e outros eventos (DA);

2. oportunidade para utilizar os conhecimentos e capacidades pessoais: determina quanto $\mathrm{o}$ ambiente inibe ou encoraja o indivíduo a utilizar e desenvolver habilidades pessoais (DA);

3. existência de objetivos gerados no meio: diz respeito a quanto o ambiente proporciona objetivos/metas a serem alcançadas pelo indivíduo (DA);
4. variedade: refere-se a quanto o ambiente proporciona estímulos variados ao indivíduo (DA);

5. clareza ambiental: concerne a quanto o ambiente deve ser compreensível, seja no planejamento de que necessitará para futuras tarefas, seja nas relações que o indivíduo estabelece com outras pessoas (DA);

6. disponibilidade econômica: refere-se a quanto as contrapartidas econômicas recebidas pelo trabalho contribuem para a sobrevivência do indivíduo na sociedade (EC);

7. Segurança física: diz respeito a quanto os ambientes protegem a pessoa de ameaças ao corpo, provendo um adequado nível de segurança, por meio do controle dos níveis de umidade, temperatura, estímulos visuais e auditivos, entre outros aspectos (EC);

8. oportunidades para desenvolver as relações interpessoais: refere-se quanto o ambiente oferece de oportunidades promotoras de interações entre as pessoas (DA);

9. posição social valorizada: concerne a quanto o trabalho implica no estabelecimento de uma posição para o indivíduo na estrutura social (EC).

Warr (1987) chama a atenção para a dinamicidade do processo e a necessidade de interpretar seu modelo a partir de uma visão não linear, mas processual. Por exemplo, a adequação da variedade do ambiente depende da competência do indivíduo e do nível de suas aspirações, nível em que o indivíduo tende a ajustar e desenvolver suas competências em compatibilidades com oportunidades do entorno.

\section{MÉTODO}

\section{População/amostra}

A presente pesquisa de campo foi desenvolvida por meio de uma amostra acidental de bancários com contrato de trabalho permanente. Em Natal, a população total de bancários é de 1.555 , sendo 402 de bancos privados e 1.153 de bancos oficiais (Sindicato dos Bancários de Natal, 2004). Participaram deste estudo 200 bancários, sendo $34,7 \%$ de bancos privados (70 bancários) e $65,3 \%$ de bancos oficiais (130 bancários). A amostra deste estudo representa, portanto, $12,86 \%$ da população.

A média de idade da amostra é de 35,8 anos. Quanto ao sexo, 58,1\% dos participantes são homens e $41,9 \%$ são mulheres. Quanto ao estado civil, a maioria 
(60,9\% dos participantes) é casada. Quanto ao nível de instrução, a maioria $(75,8 \%)$ apresenta educação superior completa. Quanto à continuidade da escolarização, 39,6\% dos participantes afirmam que continuam estudando e $60,4 \%$ não estudam.

\section{Variáveis, indicadores e instrumentos}

Tendo as dimensões da saúde mental como variáveis-critério e as condições do ambiente de trabalho no contexto da reestruturação produtivobancária como variáveis antecedentes, construiu-se um protocolo de coleta de dados com vários questionários que contemplassem essas variáveis em conformidade ao modelo ecológico de Warr (1987). O primeiro passo foi, então, examinar os questionários disponíveis e considerar sua utilização em estudos anteriores (Banks et al. 1980; Gouveia, Socorro, Andrade, Vasconcelos \& Chaves, 2003; Reis, Sheldon, Gable, Roscoe \& Ryan, 2000; Tamayo, 2002) $)^{2}$.

Para a avaliação da variável-critério saúde mental foram utilizados os seguintes questionários: Questionário de Saúde Geral - 12 (Goldberg, citado em Banks et al., 1980); Escala de Afetos Positivos e Negativos (Diener \& Emmons, 1984, citados em Reis et al., 2000); Escala de Satisfação com a Vida (Diener et al., 1985); Escala de Aspiração (construção própria).

Para avaliar os aspectos ambientais escolheu-se a Escala de Organização, Condições e Relação de Trabalho (Mendes, Rego \& Ferreira, 2004). Foram avaliados que os aspectos "Oportunidade para exercer controle sobre o meio", "Clareza ambiental", "Variedade", "Oportunidade para a utilização dos conhecimentos e capacidades pessoais" e "Objetivos gerados no meio" estão contemplados no fator Organização do Trabalho da EOCRT; o aspecto ambiental "Segurança física", no fator Condições de Trabalho da mesma escala; e o aspecto ambiental "Oportunidade para exercer relações interpessoais", no fator Relações Sociais da EOCRT.

Com relação ao aspecto "Disponibilidade Econômica", foi utilizado outro questionário para avaliá-lo, composto por duas questões: uma sobre a disponibilidade econômica e uma sobre a principal fonte de renda (dos autores Álvaro e Garrido, 2003). Quanto ao aspecto "Posição Social Valorizada" foi

2 Foram considerados os critérios de validade e consistência dos questionários, além de que se replicaram várias análises psicométricas para se assegurar da sua adequação à presente amostra (Paiva, 2005). Tais análises não serão tratadas aqui, pela necessidade de síntese. elaborada uma questão que o avalia, uma vez que não foi encontrado questionário adequado.

O protocolo de coleta de dados abrangeu ainda algumas questões mais diretas sobre o processo de reestruturação produtiva e mercado de trabalho e uma ficha sociodemográfica. As respostas a tais questões foram exploradas como variáveis de controle e como meio de se obter uma descrição da amostra.

Para operacionalizar as análises formularam-se cinco hipóteses, nas quais se relacionam as dimensões da saúde mental e os aspectos ambientais do modelo ecológico de Warr (1987):

- H1. A diminuição dos vencimentos (salários mais benefícios) observada pelos bancários tem ocasionado conseqüências psíquicas negativas.

- H2. Se os bancários estão percebendo sua posição social sendo desvalorizada, estão sentindo-se afetados negativamente na saúde mental.

- H3. Quanto melhor a percepção dos empregados da organização do trabalho, melhores os coeficientes dos indicadores de saúde mental.

- H4. Quanto melhor a percepção dos bancários das relações interpessoais mantidas nas organizações, melhores seus indicadores de saúde mental.

- H5. Quanto melhores as condições do ambiente físico, conforme percebido pelos bancários, melhores são os coeficientes dos indicadores de saúde mental.

\section{Procedimentos}

Para coletar os dados, inicialmente foram contatados os gerentes das agências bancárias, aos quais foi explicado o objetivo da pesquisa. Num segundo momento visitou-se cada agência, distribuindo-se os questionários e disponibilizando-se uma urna para estes serem depositados, o que asseguraria o sigilo e o anonimato das respostas.

As respostas dos participantes aos questionários da pesquisa foram registradas na forma de banco de dados do SPSS (Statistical Package for Social Science) for Windows, e as análises estatísticas foram desenvolvidas com a utilização de seus recursos.

\section{ANÁLISE DOS RESULTADOS}

Estimaram-se os escores nos fatores dos vários questionários conforme suas estruturas fatoriais. No que se refere às dimensões de saúde mental (Tabela 1), para se compreender os resultados deve-se observar que, como se usaram diferentes questionários, há também diferentes escalas. Por isso, 
além do desvio-padrão, foram incluídas na Tabela 1 as freqüências de participantes por intervalos das escalas.
Ambos - desvio-padrão e freqüência por intervalos são medidas de dispersão.

Tabela 1. Escores nos Indicadores de Saúde Mental

\begin{tabular}{|c|c|c|c|c|c|c|}
\hline \multicolumn{7}{|c|}{ QSG -12 (Escala de 1 a 4) } \\
\hline \multirow{2}{*}{$\begin{array}{c}\text { Fatores } \\
\text { (QSG-12) }\end{array}$} & \multirow{2}{*}{$\mathbf{N}$} & \multirow{2}{*}{ Média } & \multicolumn{3}{|c|}{ Freqüência de participantes por intervalos } & \multirow{2}{*}{ Desvio-padrão } \\
\hline & & & $\mathrm{x}<2$ & $2<x<3$ & $x>3$ & \\
\hline F1 - Depressão e Tensão Emocional & 200 & 2,07 & $56,0 \%$ & $32,0 \%$ & $12,0 \%$ & 0,63 \\
\hline F2 - Redução da auto-eficácia & 200 & 1,65 & $\mathbf{8 5}, 5 \%$ & $11,5 \%$ & $3,0 \%$ & 0,52 \\
\hline
\end{tabular}

\begin{tabular}{|c|c|c|c|c|c|c|c|c|c|}
\hline \multicolumn{10}{|c|}{ Escala de afetos positivos e negativos (Escala de 1 a 7$)$} \\
\hline \multirow[t]{2}{*}{ Fatores } & \multirow[t]{2}{*}{$\mathbf{N}$} & \multirow[t]{2}{*}{ Média } & \multicolumn{6}{|c|}{ Freqüência de participantes por intervalos } & \multirow[t]{2}{*}{ Desvio-padrão } \\
\hline & & & $X<2$ & $2<X<3$ & $3<X<4$ & $4<X<5$ & $5<X<6$ & $X>6$ & \\
\hline Afetos Positivos & 169 & 4,97 & $1,2 \%$ & $2,4 \%$ & $11,8 \%$ & $33,7 \%$ & $43,8 \%$ & $7,1 \%$ & 0,93 \\
\hline Afetos negativos & 169 & 2,69 & $26,6 \%$ & $44,4 \%$ & $20,1 \%$ & $5,9 \%$ & $2,4 \%$ & $0,6 \%$ & 0,98 \\
\hline \multicolumn{10}{|c|}{ Escala de Satisfação com a Vida (Escala de 1 a 7) } \\
\hline \multirow[t]{2}{*}{ Fator } & $\mathbf{N}$ & Média & \multicolumn{6}{|c|}{ Freqüência de participantes por intervalos } & \multirow{2}{*}{$\begin{array}{l}\text { Desvio- } \\
\text { padrão }\end{array}$} \\
\hline & & & $X<2$ & $2<X<3$ & $3<X<4$ & $4<X<5$ & $5<X<6$ & $X>6$ & \\
\hline $\begin{array}{l}\text { Satisfação com a } \\
\text { vida }\end{array}$ & 194 & 4,89 & $2,6 \%$ & $6,7 \%$ & $13,4 \%$ & $23,3 \%$ & $34,0 \%$ & $20,0 \%$ & 1,20 \\
\hline \multicolumn{10}{|c|}{ Escala de Aspirações (Escala de 1 a 5) } \\
\hline \multirow[t]{2}{*}{ Fator } & $\mathbf{N}$ & Média & \multicolumn{6}{|c|}{ Freqüência de participantes por intervalo } & \multirow{2}{*}{$\begin{array}{l}\text { Desvio- } \\
\text { padrão }\end{array}$} \\
\hline & & & $X<2$ & & $2<X<3$ & $\mathbf{3}<\mathrm{X}$ & & $X>4$ & \\
\hline Aspiração & 195 & 4,07 & $0,5 \%$ & & $5,5 \%$ & 39,29 & & $54,8 \%$ & 0,57 \\
\hline
\end{tabular}

Os resultados, na referida tabela, indicam por um lado que a saúde mental dos bancários da amostra apresenta-se satisfatória e com tendências mais positivas que negativas, corroborando as observações de Ferreira e Mendes (2001). Os afetos positivos experimentados foram mais evidentes que os negativos. Sentem-se, também, competentes e com autonomia no trabalho e apresentam alto nível de aspiração. Por outro lado, há sinais de depressão e tensão emocional em uma parte da amostra (44\% apresentam escores a partir de 2) e, também, há uma proporção de insatisfação com a vida (numa escala de 1 a 7, 44 participantes, aproximadamente um quarto da amostra, apresentam um escore até 4, e temos ainda mais 45 participantes, aproximadamente a mesma proporção, com escores entre 4 e 5). Neste sentido, os resultados corroboram estudos anteriores que indicam uma endemia de tendência depressiva entre bancários (Borges \& Argolo, 2002; Codo, Sampaio, Hitoni \& Bauer, 1995). E, em última análise, corroboram perspectivas recentes que têm assinalado a simultaneidade de vivências positivas e negativas, de satisfação e insatisfação e de prazer e sofrimento ${ }^{3}$.

3 Sugere-se consultar sobre o assunto publicações como as de: Ferreira e Mendes (2001) e Mendes e Tamayo (2001).
Todos os escores da Tabela 1, fazendo jus à noção de que todos se referem aos indicadores de um único construto - saúde mental -, são correlacionados entre si; fato que justifica aplicar a análise de clusters (Tabela 2) para identificar os tipos de funcionamento integrado, quinta dimensão da saúde mental. Encontraram-se cinco tipos de funcionamento integrado: funcionamento pleno, funcionamento depressivo-insatisfeito, funcionamento satisfatório, funcionamento depressivo e funcionamento deteriorado. Observase que nos tipos designados como depressivoinsatisfeito, depressivo e deteriorado os escores no fator Depressão e Tensão emocional tendem a ser elevados (em relação aos outros tipos), enquanto os escores no fator Aspiração tendem a ser baixos. Os escores em satisfação com a vida diferenciam destes três tipos. Estes resultados corroboram a observação anterior de uma endemia de tendência depressiva, porquanto se referem a $21,95 \%$ da amostra. Ressalva-se que nas análises subseqüentes, visando testar as hipóteses da pesquisa, desprezar-se-á o grupo de indivíduos de funcionamento deteriorado, por ser um grupo muito pequeno (4 pessoas). 
Tabela 2. Grupos de Participantes pelas Combinações dos Escores nos Diferentes Indicadores do Bem-Estar Psicológico $(\mathrm{N}=164)$

\begin{tabular}{|c|c|c|c|c|c|}
\hline \multirow[b]{2}{*}{ Indicadores de saúde mental } & \multicolumn{5}{|c|}{ Clusters } \\
\hline & $\begin{array}{c}\text { Funcionamento } \\
\text { Pleno } \\
\end{array}$ & $\begin{array}{c}\text { Funcionamento } \\
\text { Depressivo-insatisfeito }\end{array}$ & $\begin{array}{c}\text { Funcionamento } \\
\text { Satisfatório }\end{array}$ & $\begin{array}{c}\text { Funcionamento } \\
\text { Depressivo }\end{array}$ & $\begin{array}{c}\text { Funcionamento } \\
\text { Deteriorado }\end{array}$ \\
\hline $\begin{array}{l}\text { Escores no fator Depressão e } \\
\text { Tensão Emocional }\end{array}$ & 1,72 & 2,61 & 1,96 & 2,81 & 3,62 \\
\hline $\begin{array}{l}\text { Escores no fator de Redução } \\
\text { da auto-Eficácia }\end{array}$ & 1,43 & 2,00 & $\begin{array}{l}1,57 \\
1,57\end{array}$ & 2,01 & 3,52 \\
\hline $\begin{array}{l}\text { Escores no fator de satisfação } \\
\text { com a vida }\end{array}$ & 5,89 & 3,11 & 4,33 & 5,15 & 1,70 \\
\hline Escores no fator Aspiração & 4,38 & 3,39 & 4,04 & 3,95 & 2,77 \\
\hline $\begin{array}{l}\text { Escores no fator Afetos } \\
\text { Positivos }\end{array}$ & 5,56 & 4,08 & 4,96 & 4,04 & 1,95 \\
\hline $\begin{array}{l}\text { Escores no fator Afetos } \\
\text { Negativos }\end{array}$ & 2,16 & 3,59 & 2,62 & 3,81 & 5,90 \\
\hline Número de participantes & 72 & 15 & 57 & 16 & 4 \\
\hline
\end{tabular}

Quanto aos indicadores dos aspectos ambientais, deve-se também observar que foram mensurados em diferentes escalas. Esses resultados (Tabela 3) indicam que os bancários, mediante os fatores ambientais do modelo ecológico de Warr (1987), percebem de maneira positiva a organização (exercer controle sobre o meio, clareza ambiental, variedade, oportunidade para desenvolver os conhecimentos e capacidades pessoais e os objetivos gerados no meio organizacional) e as condições do trabalho (segurança física). Em contrapartida, as relações interpessoais não são percebidas de forma tão positiva, o que se pode atribuir ao fato de que aumentou a competitividade entre os bancários.

Tabela 3. Escores nos Indicadores dos Aspectos Ambientais

\begin{tabular}{|c|c|c|c|c|c|c|c|}
\hline \multicolumn{8}{|c|}{ EOCRT (Escala de 1 a 5) } \\
\hline \multirow[t]{2}{*}{ Fatores } & \multirow[t]{2}{*}{$\mathbf{N}$} & \multirow[t]{2}{*}{ Média } & \multicolumn{4}{|c|}{ Frequiência de participantes por intervalo } & \multirow[t]{2}{*}{ Desvio-padrão } \\
\hline & & & $x<2$ & $2<x<3$ & \multirow{2}{*}{$\begin{array}{l}3<x<4 \\
67,5 \%\end{array}$} & $x>4$ & \\
\hline Organização do trabalho & 200 & 3,39 & $2,0 \%$ & $20,5 \%$ & & $10,0 \%$ & 0,56 \\
\hline Condições do trabalho & 200 & 3,39 & $1,5 \%$ & $28,0 \%$ & $56,0 \%$ & $14,5 \%$ & 0,69 \\
\hline Relações de trabalho & 200 & 3,12 & $3,0 \%$ & $41,0 \%$ & $52,0 \%$ & $4,0 \%$ & 0,58 \\
\hline \multicolumn{8}{|c|}{ Escala de disponibilidade econômica (Escala de 1 a 4) } \\
\hline \multirow{2}{*}{ Fator } & \multirow{2}{*}{$\mathbf{N}$} & \multirow{2}{*}{ Média } & \multicolumn{4}{|c|}{ Frequiência de participantes por intervalo } & \multirow{2}{*}{ Desvio-padrão } \\
\hline & & & $X<1,5$ & $1,5<x<2,5$ & $2,5<x<3,5$ & $x>3,5$ & \\
\hline Disponibilidade Econômica & 199 & 2,32 & $4,5 \%$ & $60,8 \%$ & $31,2 \%$ & $3,5 \%$ & 0,62 \\
\hline \multicolumn{8}{|c|}{ Item sobre posição social valorizada (Escala de 1 a 5 ) } \\
\hline \multirow{2}{*}{\multicolumn{2}{|c|}{ Fator }} & & \multicolumn{5}{|c|}{ Freqüência de participantes por pontos atribuídos } \\
\hline & & & & 2 & 3 & 4 & 5 \\
\hline Posição social valorizada & & & & $8,5 \%$ & $24,0 \%$ & $41,0 \%$ & $23,0 \%$ \\
\hline
\end{tabular}

O bancário avalia sua situação econômica como satisfatória (Tabela 3), apresentando média de 2,32 ou tendências de escores de níveis intermediários; porém às vezes tem deixado de realizar certas atividades do dia-a-dia por falta de dinheiro. A outra questão aplicada revela que a quase-totalidade dos participantes da amostra $(93,5 \%)$ tem como única fonte de renda o próprio salário. Esses resultados pode parecer estarem acima do que a literatura revisada leva a esperar; entretanto, explorando-se a relação desta variável antecedente com as variáveis de controle, encontrou-se que ela varia com a percepção da facilidade de encontrar emprego $(F=3,99$ para $p=0,009)$. Destarte, a percepção do mercado de trabalho afeta o julgamento de adequação salarial, sendo que não esperar facilidade de encontrar 
emprego pressiona tal julgamento para cima. Desta forma, as respostas dos participantes sobre disponibilidade econômica apontam certa carga de um conformismo responsivo à situação do mercado de trabalho.

Esses resultados se refletem, por sua vez, na percepção da "Posição Social Valorizada", em que $35 \%$ dos bancários não acham que estão ocupando uma posição de prestígio na sociedade, enquanto $63 \%$ deles pensam de forma contrária. Apesar de o número daqueles que se sentem socialmente reconhecidos ser maior, não é desprezível o número dos que têm posição contrária. Este resultado certamente está refletindo a tendência de perda de estabilidade do emprego bancário indicada pela literatura.

Para testar as hipóteses da pesquisa, aplicou-se, inicialmente, a ANOVA (Análise de variância), comparando as médias obtidas pelos participantes nos fatores da EOCRT e no fator de disponibilidade econômica, segundo os tipos de funcionamento integrado (Tabela 4). Observaram-se diferenças significativas entre as médias nos três fatores da EOCRT, sendo que as médias mais baixas estão no tipo de funcionamento depressivo-insatisfeito.

Tabela 4. Análise de Variância para Tipos de Funcionamento Integrado Conforme as Variáveis Antecedentes

\begin{tabular}{|c|c|c|c|c|c|c|c|c|}
\hline \multirow{4}{*}{$\begin{array}{l}\text { Tipos de funcionamento } \\
\text { integrado }\end{array}$} & \multicolumn{8}{|c|}{ Variáveis antecedentes (indicadores dos fatores ambientais) } \\
\hline & \multicolumn{6}{|c|}{ Fatores da EOCRT } & \multirow{2}{*}{\multicolumn{2}{|c|}{ Disponibilidade Econômica }} \\
\hline & \multicolumn{2}{|c|}{ Organização no Trabalho } & \multicolumn{2}{|c|}{ Condições de Trabalho } & \multicolumn{2}{|c|}{ Relações Sociais } & & \\
\hline & M & DP & $\mathbf{M}$ & DP & M & DP & M & DP \\
\hline Pleno & 3,58 & 0,51 & 3,58 & 0,51 & 3,56 & 0,64 & 2,4 & 0,62 \\
\hline Satisfatório & 3,40 & 0,45 & 3,40 & 0,45 & 3,45 & 0,48 & 2,2 & 0,55 \\
\hline Depressivo & 3,07 & 0,57 & 3,07 & 0,57 & 3,23 & 0,61 & 2,3 & 0,71 \\
\hline Depressivo-Insatisfeito & 2,99 & 0,64 & 2,99 & 0,64 & 2,82 & 0,56 & 2,2 & 0,67 \\
\hline Total & 3,41 & 0,54 & 3,41 & 0,54 & 3,42 & 0,61 & 2,3 & 0,61 \\
\hline \multirow{2}{*}{ ANOVA } & $\mathrm{F}$ & $\mathrm{p}$ & $\mathrm{F}$ & $\mathrm{p}$ & $\mathrm{F}$ & $\mathrm{p}$ & $\mathrm{F}$ & $\mathrm{p}$ \\
\hline & 8,55 & 0,001 & 5,47 & 0,001 & 7,43 & 0,001 & 1,6 & 0,19 \\
\hline
\end{tabular}

Legenda: M (média) e DP (Desvio-padrão).

Em relação ao último indicador dos aspectos ambientais (posição social valorizada), considerandose que foi mensurado por um item isolado, aplicou-se o qui-quadrado, resultando em: $\chi^{2}=27,68$ e $p=0,001$. Observa-se, então, que aqueles indivíduos que apresentaram o funcionamento integrado designado por Funcionamento pleno são os que mais tendem a atribuir a pontuação máxima (Posição social muito valorizada), porém são igualmente os mais dispersos, pois entre eles há também proporções relevantes, divididas entre os níveis valorizados e valorizados medianamente (respectivamente $43,1 \%$ e 20,8\%). Observa-se que todas as distribuições guardam a semelhança de traçarem curvas convexas, porém $\mathrm{o}$ ponto de mudança da inclinação as diferencia, deslocando-se da esquerda para a direita na seguinte ordem: funcionamento depressivoinsatisfatório, satisfatório, depressivo e, finalmente, pleno.

Destarte, todos os coeficientes encontrados confirmam as hipóteses apresentadas, com exceção da primeira delas, quando o indicador de saúde mental utilizado é o funcionamento integrado.
Passou-se, então, a testar as mesmas hipóteses levando-se em conta os demais indicadores de saúde mental. Estimaram-se os coeficientes de correlação de Pearson (Tabela 5) entre os demais indicadores de saúde mental e os indicadores dos fatores ambientais, com exceção da posição social valorizada. Os resultados mostram que os escores nos fatores da EOCRT são correlacionados em níveis estatisticamente significativos com todos os indicadores de saúde mental. Os escores no fator "Disponibilidade Econômica", porém, correlacionam-se em níveis estatisticamente significativos com os escores nos fatores "Redução da Auto-eficácia" e "Satisfação com a Vida". Verifica-se que o resultado entre os escores de "Satisfação com a vida" é diretamente proporcional ao fator ambiental "Disponibilidade econômica", o que comprova a hipótese de que quanto maiores são as possibilidades econômicas do indivíduo, melhor é o seu bem-estar psicológico. Em relação ao fator "Redução da auto-eficácia", observa-se uma correlação negativa com o fator "Disponibilidade econômica", o que sugere que quanto maiores as possibilidades econômicas do bancário, menores são as possibilidades de perceber-se com reduzida auto-eficácia. 
Tabela 5. Correlações entre os Escores no Fator "Disponibilidade Econômica" e os Escores nos Indicadores de Saúde Mental.

\begin{tabular}{|c|c|c|c|c|c|}
\hline \multirow[b]{2}{*}{ Indicadores de saúde mental } & & \multirow{2}{*}{$\begin{array}{l}\text { Disponibilidade } \\
\text { econômica }\end{array}$} & \multicolumn{3}{|c|}{ Fatores da EOCRT } \\
\hline & & & $\begin{array}{c}\text { Organização do } \\
\text { Trabalho }\end{array}$ & $\begin{array}{c}\text { Condições de } \\
\text { Trabalho }\end{array}$ & Relações de Trabalho \\
\hline \multirow{3}{*}{$\begin{array}{l}\text { Escores no fator Depressão e Tensão } \\
\text { Emocional do QSG-12 }\end{array}$} & $r$ & $-0,104$ & $-0,37$ & $-0,33$ & $-0,38$ \\
\hline & $p$ & 0,145 & $<0,001$ & $<0,001$ & $<0,001$ \\
\hline & $N$ & 199 & 200 & 200 & 200 \\
\hline \multirow{3}{*}{$\begin{array}{l}\text { Escores no fator de Redução da auto- } \\
\text { eficácia do QSG-12 }\end{array}$} & $r$ & $-0,149$ & $-0,25$ & $-0,33$ & $-0,41$ \\
\hline & $p$ & 0,036 & $<0,001$ & $<0,001$ & $<0,001$ \\
\hline & $N$ & 199 & 200 & 200 & 200 \\
\hline \multirow{3}{*}{ Escores no fator Satisfação com a Vida } & $r$ & 0,236 & 0,19 & 0,37 & 0,39 \\
\hline & $p$ & 0,001 & 0,007 & $<0,001$ & $<0,001$ \\
\hline & $n$ & 193 & 193 & 193 & 193 \\
\hline \multirow{3}{*}{ Escores no Fator Aspiração } & $r$ & 0,104 & 0,24 & 0,44 & 0,41 \\
\hline & $p$ & 0,145 & 0,001 & $<0,001$ & $<0,001$ \\
\hline & $N$ & 199 & 199 & 199 & 199 \\
\hline \multirow{3}{*}{ Escores no fator Afetos Positivos } & $r$ & 0,075 & 0,25 & 0,25 & 0,26 \\
\hline & $p$ & 0,332 & 0,01 & 0,001 & 0,001 \\
\hline & $N$ & 168 & 169 & 169 & 169 \\
\hline \multirow{3}{*}{ Escores no fator Afetos Negativos } & $r$ & $-0,139$ & $-0,35$ & $-0,24$ & $-0,42$ \\
\hline & $p$ & 0,073 & $<0,001$ & 0,002 & $<0,001$ \\
\hline & $N$ & 168 & 169 & 169 & 169 \\
\hline
\end{tabular}

Legenda: $r$ (coeficiente de correlação de Pearson), e $N$ (número de participantes).

Tais coeficientes de correlação corroboram os resultados encontrados em relação ao funcionamento integrado, pois aqueles indicadores dos fatores ambientais que apresentavam diferenças de médias por tipos de funcionamento integrado mostram correlacionar-se também com todos os indicadores de saúde mental um a um, enquanto que aquele indicador - disponibilidade econômica - que não apresentou diferenças entre as médias, mostrou-se correlacionado significativamente $(\mathrm{p}<0,05)$ apenas com dois indicadores isolados de saúde mental - Redução da Auto-eficácia (do QSG-12) e Satisfação com a Vida. Isto significa que, apesar de a disponibilidade econômica não afetar a saúde mental em seu conjunto, afeta alguns de seus aspectos.

Como, não obstante, havia sido observado que os escores em "Disponibilidade Econômica" eram correlacionados com a tendência de perceber, ou não, facilidade de encontrar emprego no mercado, estimaram-se correlações parciais entre os escores de "Disponibilidade econômica" e os indicadores de saúde mental. Os resultados indicaram que aqueles coeficientes que já eram significativos (Tabela 5) cresceram um pouco em magnitude e dois passaram a ser significativos: com "Depressão e Tensão Emocional" e com "Afetos Negativos". Tais resultados indicam que aqueles que não percebem facilidade em encontrar emprego no mercado não apenas são mais vulneráveis a vivenciar tais afetos, mas também avaliam como pior sua situação econômica.
Além da variação conjuntural da avaliação da disponibilidade econômica, já mencionada, a literatura resumida na parte introdutória deste artigo indica que a relação entre a "situação econômica" e a saúde mental não é linear, pois apresenta uma relação designada como efeito adicional. Por isso foram traçados gráficos entre situação econômica e cada indicador de saúde mental (exceto funcionamento integrado), identificando o ponto de mudança da direção da relação entre as variáveis. Observou-se, então, que em tais gráficos não se revelam mudanças de sinais da relação, mas apenas tendência à perda de inclinação na curva, corroborando a classificação da variável de EC de Warr (1987). Tomouse o ponto onde isto se configura (escore 1,5) como ponto de corte da distribuição dos escores de "Disponibilidade econômica" e os coeficientes de correlação de Pearson foram reestimados, considerando-se a distribuição apenas a partir de tal ponto de corte. Observou-se, então, uma modificação acentuada no coeficiente de correlação entre os escores no fator "Disponibilidade econômica" e os escores no fator de "Afetos negativos", que passou a ser estatisticamente significativa $(r=-0,21$ para $p=0,009)$. Tal relação é inversamente proporcional, significando que os "Afetos negativos" diminuem à proporção que aumenta a "Disponibilidade econômica".

Em referência à segunda hipótese - se os bancários estão percebendo sua posição social como desvalorizada, estão sentindo-se afetados negativamente na saúde mental - compararam-se as médias dos diversos indicadores entre os participantes da amostra, conforme os pontos que 
atribuíram à posição social valorizada, e aplicou-se ANOVA para permitir avaliar as diferenças encontradas entre as médias. Os resultados gerados por tais procedimentos indicam diferenças significativas nas médias de três indicadores de saúde mental, quais sejam: fator "Redução da auto-eficácia" $(F=5,10 ; p=0,002)$, "Satisfação com a vida" $(F=4,62 ; \quad p=0,004)$ e "Aspiração" ( $F=14,32 ; p=0,001)$.

Assim, quando se observam as médias destes fatores de saúde mental, nota-se que as médias nos fatores "Satisfação com a vida" e "Aspiração" crescem à medida que os indivíduos atribuem mais pontos à "Posição social valorizada", ocorrendo o contrário com as médias no fator de "Redução da auto-eficácia". Observa-se, portanto, não só uma relação entre as variáveis, mas certa linearidade, o que pode ser visto nas médias das três variáveis por níveis atribuídos à posição social.

\section{CONSIDERAÇÕES FINAIS}

A maior parte dos resultados corroborou as hipóteses da pesquisa, sugerindo haver relação entre o ambiente de trabalho - suas condições físicas, relações sociais de trabalho e outros aspectos - e a saúde mental dos bancários. Apenas a primeira hipótese foi corroborada parcialmente, pois os resultados relacionaram a situação econômica apenas com alguns indicadores da saúde mental. Quando exploradas mais detidamente as relações de disponibilidade econômica com a saúde mental, o que ficou visível foi a complexidade da relação, a qual é mediada pela percepção de oportunidades de emprego no mercado de trabalho e não é uma relação linear. Por outro lado, constatou-se linearidade entre algumas variáveis que fugiam ao esperado pelo modelo ecológico de saúde mental que fundamentou a pesquisa. Os resultados levam a pensar que as relações ambientais com a saúde são do tipo DA e/ou EC, dependem dos indicadores de saúde mental considerados e ainda sofrem a mediação da visão do indivíduo sobre o mercado de trabalho e o contexto mais amplo.

$\mathrm{O}$ fato de os resultados corroborarem todas as hipóteses apóia o modelo adotado, mas em si não esclarece o que se deve focar para promover o bem-estar do bancário e minimizar a endemia de tendências depressivas. Se o leitor, entretanto, considerar os resultados apresentados sobre os aspectos ambientais, encontrará, ao menos, uma resposta: todas as variáveis antecedentes afetam as variáveis-critério (indicadores de saúde mental), mas a organização e as condições de trabalho são bem vistas pelo bancário, o que significa que o impacto sobre sua saúde mental é no sentido de promovê-la. O inverso ocorre com relações sociais e disponibilidade econômica, variáveis que no setor bancário estão afetando desfavoravelmente a saúde mental. Neste sentido importa recordar que as correlações de maiores magnitudes dos escores em Depressão e Tensão emocional são exatamente com organização e relações do trabalho. Um aspecto do ambiente, então, promove a saúde, enquanto o outro contribui para sua deterioração. É por isso que no geral se tem uma impressão de uma saúde mental satisfatória.

Vistos de tal ângulo, os resultados encontrados corroboram o que tem sido assinalado por Heloani (1996): que no contexto da reestruturação produtiva, os empregados tendem a ser "seduzidos" pela organização e gestão do trabalho e se alienam da busca de seus direitos socioeconômicos, entre outros aspectos. São controlados pelo próprio gosto que sentem pelas tarefas. Por isso, dedicam-se desenfreadamente às atividades de trabalho.

Esta perspectiva de compreensão dos resultados é importante para, a partir dela, vários segmentos (sindicalismo, sistema de saúde pública, gestão organizacional) pensarem suas linhas de ação para promover a saúde. Mas há outro aspecto ainda a ser enfatizado: é muito grande a distância entre a visão alimentada pela sociologia do trabalho e a forma como o bancário concreto percebe seu trabalho. Entende-se aqui que tal divergência ocorre, em parte, pela forma de enfrentamento cognitivo do bancário à sua situação vivencial, em que ele usa táticas carregadas de conformismo. Tal situação só pode ser mudada abrindo-se formas alternativas de lidar com a situação sem confrontar seu atual encantamento pelo conteúdo do que faz, mas antes ajudando a pôr tal encantamento no seu lugar, evitando que substitua outros prazeres da vida humana.

Por fim, é preciso registrar aqui alguns limites da presente pesquisa. $O$ primeiro deles é a representatividade da amostra no que diz respeito à forma acidental da escolha dos participantes. $\mathrm{O}$ segundo é a necessidade de a presente pesquisa ser completada por outras com técnicas qualitativas para aprofundar a forma de os bancários fazerem a leitura da realidade, enfim, como elaborarem suas cognições de forma a tornar a realidade mais agradável do que a indicada pelos dados sociológicos. O terceiro é a evidente necessidade de maiores explorações sobre as relações entre as variáveis antecedentes e o critério para compreender quando estas apresentam uma característica linear, de DA ou de EC. Observe-se que a pergunta que entendemos dever ser feita não é qual o tipo de relação, mas quando e em que condições as relações entre as variáveis serão de um tipo ou de outro. 


\section{REFERÊNCIAS}

Álvaro, J. L., \& Garrido, A. (2003). Escala sobre situação econômica (Protocolo de pesquisa não publicado).

Araújo, A. M. C., Cartoni, D. M., \& Justo, C. R. D. M. (2001). Reestruturação produtiva e negociação coletiva nos anos 90 . Revista brasileira de ciências sociais, 16(45), 85-112.

Banks, M. H., Clegg, C. W., Jackson, P. R., Kemp, N. J., Stafford, E. M., \& Wall, T. D. (1980). The use of the General Health Questionnaire as an indicator of mental health in occupational studies. Journal of Occupational Psychology, 53, 187-194.

Borges, L. O., \& Argolo, J. C. T. (2002) Adaptação e validação de uma escala de bem-estar psicológico para uso em estudos ocupacionais. Revista de Avaliação Psicológica, 1, 17-27.

Brasil, Ministério do Trabalho (1965). Lei No. 4.923, de 23 de dezembro de 1965 (D.O.U. de 29/12/65, LTr 30/91). Recuperado em 03 março, de 2008 em http://wwa.dape.net/downloads/programas/mte/LeiN4.923.pdf

Bücher, J. S. N. F. (2003). Psicologia da saúde no contexto da saúde pública: uma complexidade crescente. Em O. H. Yamamoto \& V. V. Gouveia. (Orgs.), Construindo a Psicologia brasileira: desafios da ciência e prática psicológica (pp. 213-237). São Paulo: Casa do Psicólogo.

Capra, F. (1982). O Ponto de Mutação. São Paulo: Cultrix.

Codo, W., Sampaio, J. J. C., Hitoni, A. H., \& Bauer, M. (1995). A síndrome do trabalho vazio em bancários. Em W. Codo \& J. J. C. Sampaio (Orgs.), Sofrimento psíquico nas organizações: saúde mental e trabalho. Petrópolis: Vozes

DIEESE (1997). Reestruturação Produtiva Reduz Emprego nos Bancos. Boletim DIEESE, 196, 9-14. Recuperado em 20 março, de 2003 em www.dieese.org.br/esp/estjul97.html

Diener, E., Emmos, R. A., Larsen, R. J., \& Griffin, S. (1985). The satisfaction with life scale. Journal of Personality Assessment, 49, 71-75.

Ferreira, A. B. H. (1986). Novo dicionário da língua portuguesa. Rio de Janeiro: Nova Fronteira.

Ferreira, M. C., \& Mendes, A. M. (2001). "Só de pensar em vir trabalhar, já fico de mau humor": atividade de atendimento ao público e prazer-sofrimento no trabalho. Estudos de Psicologia, 6(1), 93-104,

Filgueiras, L. (2001). Reestruturação produtiva e emprego bancário. Em A. Gomes (Org.), O trabalho no século XXI: considerações para o futuro do trabalho (pp. 279-299). São Paulo: A. Garibaldi.

Garay, A. B. S. (2001). Reestruturação produtiva e desafios de qualificação: algumas considerações críticas. Recuperado em 25 janeiro, de 2003 em http://www.ufmt.br

Gouveia, V. V., Socorro, T. C., Andrade, J. M., Vasconcelos, T. C., \& Chaves, S. S. S. (2003). Estudo de validação da Escala de satisfação com a vida [Resumo]. Em Conselho Regional de Psicologia - $13^{\text {a }}$ Região (Org.), I Encontro Paraibano de Avaliação e Medida em Psicologia. A diversidade da avaliação psicológica no contexto da sociedade contemporânea. Resumos de comunicações científicas (pp. 41-42). João Pessoa: Conselho Regional de Psicologia - $13^{\text {a }}$ Região.

Heloani, R. (1996). Organização do trabalho e administração: uma visão multidisciplinar. São Paulo: Cortez.

Laranjeiras, S. M. G. (1997). Reestruturação produtiva no setor bancário: a realidade dos anos 90. Revista Educação \& Sociedade, 61. Recuperado em 10 janeiro, de 2003 em http://www.scielo.br

Mendes, A. M. B., Rego, V. B., \& Ferreira, M. C. (2004). Avaliando as Condições, Organizações e Relações Sociais de Trabalho [Resumo]. Em I Congresso Brasileiro de Psicologia Organizacional e do Trabalho, Salvador. Recuperado em 15 janeiro, de 2007 em http:www.sbpot.org.br/site/congresso

Mendes, A. M., \& Tamayo, A. (2001). Valores organizacionais e prazer-sofrimento no trabalho. PSICO-USF, 6(1), 39-46.

Ogden, J. (1999). Psicologia da Saúde. Lisboa: Climepsi.

Organização Mundial de Saúde (1948). Recuperado em 11 agosto, de $2003 \mathrm{em} \mathrm{http://www.who.int/about/es/}$

Paiva, C. S. D. L. (2005). O ambiente de trabalho no setor bancário e o bem-estar. Dissertação de Mestrado Não-Publicada. Programa de Pós-Graduação em Psicologia, Universidade Federal do Rio Grande do Norte, Natal.

Reis, H. T., Sheldon, K. M., Gable, S. L., Roscoe, J., \& Ryan, R. M. (2000). Daily well-being: The role of autonomy, competence, and relatedness. Personality and Social Psychology Bulletin, 26, 419435.

Segnini, L. R. P. (1999). Reestruturação nos bancos no Brasil: desemprego, subcontratação e intensificação do trabalho. Educação e Sociedade, 67(20), 1-19.

Spink, M. J. P. (1992). Psicologia da saúde: a estruturação de um novo campo de saber. Em F. C. B. Campos (Org.), Psicologia e Saúde: repensando práticas (pp. 11-21). São Paulo: Hucitec.

Tamayo, M. R. (2002). Burnout: relações com a afetividade negativa, o coping no trabalho e a percepção e suporte organizacional. Tese de Doutorado não publicada, Programa de Pós-Graduação em Psicologia, Universidade de Brasília, Brasília.

Vaitsman, J. (1992). Saúde, cultura e necessidades. Em S. Fleury (Org.), Saúde Coletiva? - Questionando a Onipotência do Social (pp. 157-173). Rio de Janeiro: Relume Dumará.

Warr, P. (1987). Work, unemployment and mental health. New York: Clarendon.

WHO (1948). Constitution Of World Health Organization. New York: WHO. Recuperado em 11 agosto, de 2003 em http://www.who.int/about/es/.html

Recebido em 17/11/2006

Aceito em 11/05/2007 $\begin{array}{ll}\text { Endereço para correspondência : } & \text { Cynthia Suennia Damasceno Lucena de Paiva. Rua Umbelino Fonseca, quadra 24 lote 3, casa 2, Setor } \\ & \text { Morada do Sol, CEP: 75909-090, Rio Verde-GO, Brasil. E-mail: cynthia_23@supercabo.com.br }\end{array}$ 